\title{
Numerical simulation of the morphodynamics of the Gold Coast Seaway
}

\author{
$\underline{\text { M. Sedigh }}^{\text {a }}$, R. Tomlinson ${ }^{\text {b }}$, N. Cartwright ${ }^{c}$ and A. Etemad-Shahidi ${ }^{c}$ \\ ${ }^{a}$ School of Engineering \& Griffith Centre for Coastal Management, Griffith University, Gold Coast Campus, \\ Qld 4222, Australia, \\ Email: mahnaz.sedigh@griffithuni.edu.au \\ ${ }^{b}$ Griffith Centre for Coastal Management, Griffith University, Gold Coast Campus, Qld 4222, Australia \\ ${ }^{c}$ Griffith School of Engineering, Griffith University, Gold Coast Campus, Qld 4222, Australia
}

\begin{abstract}
Sediment transport and morphological change in the Gold Coast Seaway area, located on the east coast of Australia, were studied numerically. The main reason for the study was to understand the pattern of morphological evolution in the area with a focus on the ebb-tidal delta to examine the processes leading to its morphological change and gradual growth; despite the fact that a sand bypassing system has been implemented and operated since the entrance stabilization in 1986. The model used was MIKE 21 which is a depth averaged flexible mesh model which couples flow, wave and sediment transport. The model was run for a ten month period during which significant morphological evolution and delta growth was observed based on two subsequent bathymetry surveys. Model sensitivity to various input parameters such as wave directional standard deviation, wave breaking coefficient, sediment grain size and wave theory formulation were discussed. The simulated accumulative longshore sediment transport showed a good agreement with previous estimates. Although the model was unable to account for the movement of sediment resulting from the artificial sand bypassing system, it still simulated gradual natural sand bypassing around the offshore edge of ebb-tidal delta consistent with studies of other ebb-tidal delta locations devoid of an artificial bypassing system. The predicted trend of seabed level changes during the ten months, ignoring the artificial sand bypass system, also showed a tendency for northward migration of the inlet channel due to the dominant direction of the littoral current. This finding was consistent with the previous historical analysis of the entrance before stabilisation. During low energy wave conditions, the majority of the littoral drift accumulated to the south of the jetty. This resulted in erosion of the downstream coastline as well as the central part of the ebb-tidal delta. The cross shore distribution of the littoral drift confirmed the occurrence of a significant volume of longshore sediment transport further offshore from the seaward end of the bypassing jetty as well as the southern training wall, especially during storm events. It is suggested that this leakage partially passed the ebb-tidal delta through natural sand bypassing, but was mainly trapped on the ebb-tidal delta in response to the interaction of longshore, wave induced and ebb currents. Therefore, it is suggested that the growth of the ebb-tidal delta is mainly due to the leakage of littoral drift past the sand bypassing jetty and southern training wall. The results also showed that storm events, and in this case mainly the East Coast Low (ECL) in May 2009, play a major role in controlling the morphological evolution of the ebb-tidal delta. The model skill was therefore assessed quantitatively for simulated bed level changes in response to ECL 2009 event in comparison with the observed morphological changes over the ten month period using an adjusted Brier Skill Score. The skill results in this comparison show that the model performed well.
\end{abstract}

Keywords: $\quad$ Morphological simulation, ebb-tidal delta, Skill Score, sediment transport 


\section{INTRODUCTION}

The Nerang river entrance, now known as the Gold Coast Seaway (GCS), was stabilised in 1985 to overcome the navigation safety issues in the inlet channel due to the fast northward migration of the natural entrance. The morphological behaviour of the entrance, since then, has been the subject of several studies (Munday, 1995; WRL and GCCM, 1998; Andrews and Nielsen, 2001; Sennes et al., 2007). After the entrance stabilisation, one of the main challenges in maintaining the navigable channel is the continuous growth of the ebb-tidal delta shoal in the mouth of the entrance despite the fact that a sand bypassing system has been developed, shortly after the entrance stabilization (1986), to bypass the longshore sediment transport. This concern leading to dredging activities at the river mouth, which is both time and budget consuming.

In this paper a calibrated and verified hydrodynamics model, which was explained in Sedigh et al. (under review), was used to simulate the morphological behaviour of the GCS. The main purpose of this study was to develop a real-time calibrated process-based morphological model with a reasonable skill in simulation of the morphological evolution in the research area, specifically GCS ebb-tidal delta. This model can help to understand the governing factors for morphological evolution of the ebb-tidal delta, sand transport pathways and rates, and to investigate the possible sand sources for the growing ebb-tidal delta.

\section{STUDY AREA}

The GCS is a trained tidal inlet which is located on the Australian East coast, Gold Coast City (Figure 1). It was trained in 1985 with two training walls, and shortly after a sand bypassing system was implemented and completed to compensate for the interrupted littoral drift (Sennes et al., 2007). The annual rate of northward littoral drift is variable and depends on the location, frequency and intensity of the storms (Patterson, 2007; Splinter et al., 2011). The average rate of net northward longshore transport for the Gold Coast beaches is about 500,000 $\mathrm{m}^{3} / \mathrm{yr}$ (Delft, 1970; 1992). Sediment along the Gold Coast consists of well sorted fine sand with a grading coefficient of about 1.25 based on the collected samples from the field. The mean grain size varies spatially with a dominant $d_{50}$ of $200 \mu \mathrm{m}$ in the nearshore area (Delft, 1970).

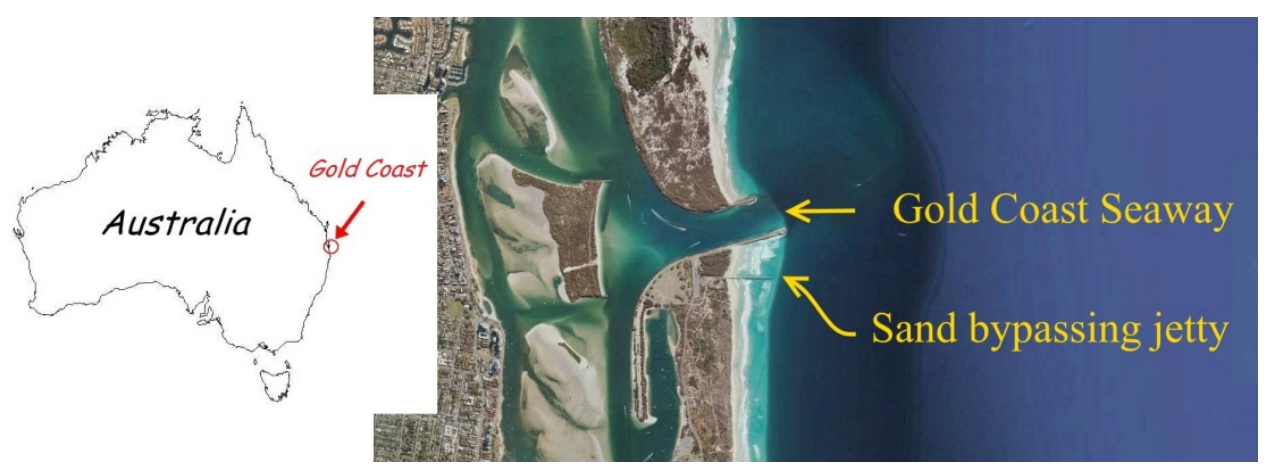

Figure 1. Gold Coast Seaway and the Sand bypassing system location

The ebb-tidal delta at the inlet mouth has been growing since 1986 , initially at the rate about $185,000 \mathrm{~m}^{3} / \mathrm{yr}^{2}$ (WRL and GCCM, 1998) until 1992. Then, this rate decreased to approximately $75,000 \mathrm{~m}^{3} / \mathrm{yr}$ until 1998 . In more recent years, from 2004 to 2009, this rate was estimated to be about 90,000 $\mathrm{m}^{3} / \mathrm{yr}$ (Sedigh et al., 2012). This continuous growth of the ebb-tidal delta endangers navigation systems at the entrance; therefore, dredging is periodically planned to maintain accessibility of the channel. Numerical simulations of the morphodynamics of the inlet region can help to achieve a better understanding of the morphodynamics of the system and thus assist in making better informed coastal management decisions.

\section{NUMERICAL MODELLING}

A numerical model, using MIKE 21/3 coupled model, was developed to simulate the morphodynamics of the tidal inlet. The hydrodynamics of the model were initially calibrated and verified against wave and current measurements (Sedigh et al., under review), then the model was applied for morphological simulation of the case study. All of the simulations were performed in 2DH (Depth Averaged) due to two main reasons. First, the computational time was a constraint in this study and using a $3 \mathrm{D}$ simulation increases the simulations time significantly. Second, it has been shown in several studies that $2 \mathrm{DH}$ models are capable of simulating and reproducing the behaviour of tidal inlets effectively (e.g. Tung, 2011). The chosen morphological simulation time was a ten month period from August 2008 till June 2009 (two consecutive survey data collections) during which a significant amount of morphological changes occurred. The simulation time for 
ten month simulation was about two weeks using a 64-bit Windows machine, which has an Intel core Xeon CPU X5670, $2.93 \mathrm{GHz}$, and a 12GB RAM.

The model was initially run using mainly default parameters (engineering approach) for the ten month period. The results demonstrated that a significant amount of morphological evolution at the ebb-tidal delta occurred during the major storm events, particularly the East Coast Low (ECL) in 19-25 May 2009 (with maximum significant wave height of 6 metres at the Gold Coast Buoy, located about $1 \mathrm{~km}$ offshore with the water depth of about 17 metres). According to that, and also because of the computational cost of ten month simulations, sensitivity analyses to various factors were investigated initially only for the ECL in 2009 duration. Then the optimised model was applied for the ten month simulations. In the following section a brief description of some of the simulation settings is provided.

\subsection{Sensitivity to HD and SW module parameters}

The sensitivity of morphological evolution to some of the HD (Hydrodynamic) and SW (Spectral wave) modules was found to be negligible. These include bottom friction in the SW module and eddy viscosity in the HD module. The bottom friction in the SW module was adjusted as constant $\mathrm{d}_{50}$ of $200 \mu \mathrm{m}$ based on field measurements, and the eddy viscosity in the HD module was adjusted to constant default Smagorinsky formulation for the whole domain area. It should be considered that some of the parameters, such as bed resistance in the HD module, were previously applied as HD simulation calibration factors, and cannot vary in the coupled HD-SW-ST (Sediment Transport) model. Wave breaking parameter $(\gamma)$ and directional standard deviation (DSD) were two of the SW module input parameters that were found to significantly affect the beach erosion and the succeeding littoral transport. The first one affects the cross-shore length of the surfzone in which the wave energy dissipates, and the second one affects the direction that waves propagate and therefore the intensity of the induced longshore current by the breaking of oblique waves. The best sediment transport and morphological changes results were achieved by incorporating constant DSD of 20 degrees and $\gamma$ of 0.9 for the whole domain area.

\subsection{Application of different wave theories}

When combined current and wave actions are included, the sediment transport rate is found from linear interpolation in a sediment transport table which is generated beforehand by a quasi-three-dimensional sediment transport model (STPQ3D). In developing the sediment transport table, a number of wave theories can be applied to calculate the wave motion outside the bottom boundary layer. Both classical and semi empirical non-linear wave theories are available in the model (Table 1), although it was noted by DHI (2014) that no wave theory exists that covers all hydrodynamic conditions perfectly.

Table 1. Wave theories applied in STPQ3D model and their application area

\begin{tabular}{|c|c|c|c|}
\hline Classic theories & Application area & Semi empirical theories & Application area \\
\hline $\begin{array}{l}\text { Stokes theory 1st, 3rd and 5th } \\
\text { Order (Fenton, 1985) }\end{array}$ & $\begin{array}{l}\text { Deep water/ Non- } \\
\text { breaking waves }\end{array}$ & $\begin{array}{l}\text { Isobe and Horikawa } \\
(\underline{1982})\end{array}$ & $\begin{array}{l}\text { All water depths/Breaking and Non- } \\
\text { breaking waves }\end{array}$ \\
\hline $\begin{array}{l}\text { Cnoidal theory } 1 \text { st, } 3 \text { rd and } 5 \text { th } \\
\text { Order ( } \underline{\text { Fenton, } 1990)})\end{array}$ & $\begin{array}{l}\text { Shallow water/ Non- } \\
\text { breaking waves }\end{array}$ & $\begin{array}{l}\text { Doering and Bowen } \\
(\underline{1995)}\end{array}$ & $\begin{array}{l}\text { All water depths/Breaking and Non- } \\
\text { breaking waves }\end{array}$ \\
\hline Vocoidal theory ( $\underline{\text { Swart, 1982) }}$ & $\begin{array}{l}\text { All water depths/Non- } \\
\text { breaking waves }\end{array}$ & & \\
\hline
\end{tabular}

The simulation of the storm period was performed using the various wave theories in sediment transport calculation, and the resultant bed level change was qualitatively compared with that of survey data. Although the major focus of this study is on the morphological evolution of the ebb-tidal delta, the morphological evolution of the adjacent beaches was also considered, since their erosion and cross shore distribution of resultant longshore sediment transport can affect the ebb-tidal delta evolutions. The results have shown that classic theories, in which wave breaking were not included, underestimate the beach erosion, the resultant longshore sediment transport and the subsequent accretion on the offshore bar, as well as the leakage to the entrance mouth. Generally with a $\mathrm{d}_{50}$ of $200 \mu \mathrm{m}$, the delta crest erosion was overestimated in all models; while between the two available semi empirical theories, Isobe and Horikawa (1982) overestimated the sediment transport on the delta crest more than did Doering and Bowen (1995). Therefore, the latter was applied for consecutive simulations. 


\subsection{General sediment transport parameters}

In calculating the sediment transport table some of the parameters, such as sediment relative density (2.55), the critical value of shields parameter $(0.045)$ and water temperature $\left(20^{\circ} \mathrm{C}\right)$ were calculated or adjusted based on the collected field data. The influence of ripples, bed slope and streaming were selected to be included in determining the rate of sediment transport in the generation of the sediment transport table. Previous studies and the analysis of the collected sand samples have shown that there is a spatial variability in sediment mean grain size in the GCS region with a more dominant $\mathrm{d}_{50}$ of about $200 \mu \mathrm{m}$ in the nearshore area (Delft, 1970). There is no data reflecting the more recent trend of spatial distribution of $\mathrm{d}_{50}$ in the area; therefore, constant $d_{50}$ of $200 \mu \mathrm{m}$, as suggested for the nearshore area by Delft (1970), was applied in this study. The littoral sediment fluxes, as well as the morphological evolution of the area, were found to be highly sensitive to the adjusted sediment grain size in the area similar to previous studies (Pinto et al., 2006; Fortunato et al., 2014). It should be also noted that all of the open boundaries were defined as boundaries with zero sediment flux gradient for outflow and zero bed change for inflow.

\subsection{Model performance}

The model accuracy in the vicinity of the ebb-tidal delta was assessed using the simulated morphological evolution during the ECL in 2009 due to three main reasons. First, the ten months simulation suggested that most of the morphological evolution occurred during the ECL in 2009. Second, due to the limitation of the model, mechanical sand bypassing simulation was not practical and accurate simulation of the calmer periods where the bypassing is influential was not possible. Third, according to the more onshore cross-shore distribution of longshore sediment transport in the lower wave energy period, it can be assumed that the artificial bypassing system captured most of the littoral drift and the leakage of littoral drift to the ebb-tidal delta is relatively small.

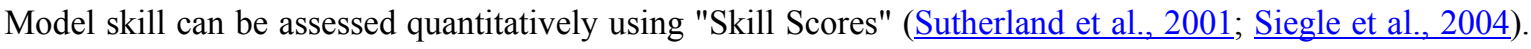
These are used as an estimation of accuracy of prediction relative to the accuracy of a baseline prediction. One of the most commonly used Skill scores is the Brier Skill Score (BSS) and Adjusted Brier Skill Score (ABSS), which are based on Mean Square Error (MSE) as shown in equations (1) and (2) (Van Rijn et al., 2003; Sutherland et al., 2004). These range from less than zero, which represents no agreement, to 1 which represents perfect agreement (see Table 2).

$$
\begin{aligned}
& B S S=1-\frac{\operatorname{MSE}\left(z_{c}, z_{m}\right)}{\operatorname{MSE}\left(z_{0}, z_{m}\right)}=1-\frac{\sum\left(z_{c}-z_{m}\right)^{2}}{\sum\left(z_{0}-z_{m}\right)^{2}} \\
& A B S S=1-\frac{\sum\left(\left|z_{c}-z_{m}\right|-\Delta z_{m}\right)^{2}}{\sum\left(z_{0}-z_{m}\right)^{2}}
\end{aligned}
$$

where $z_{c}$ is a set of $N$ computed/predicted by model bed

Table 2. Proposed classification for the quality of morphological prediction based on Brier skill score (Van Rijn et al., 2003; Sutherland et al., 2004)

\begin{tabular}{lll}
\cline { 2 - 3 } & BSS & ABSS \\
\hline Excellent & $1.0-0.5$ & $1.0-0.8$ \\
Good & $0.5-0.2$ & $0.8-0.6$ \\
Reasonable/fair & $0.2-0.1$ & $0.6-0.3$ \\
Poor & $0.1-0$ & $0.3-0$ \\
Bad & $<0$ & $<0$ \\
\hline
\end{tabular}

level values, $z_{m}$ is a set of $N$ observed/measured bed levels, $z_{0}$ is the initial bed levels, $\Delta z_{m}$ is measurement error which is set to $0.2 \mathrm{~m}$ based on surveying accuracy. It should be noted that negative values of the term in ABSS's numerator bracket is set to zero.

\section{RESULTS AND DISCUSSION}

The results of the ten month morphological simulation are shown in Figure $3 b$. Overall; the ten month simulation predicted the expected dynamics of the inlet. These include: (1) the annual accumulative longshore sediment transport of approximately $500,000 \mathrm{~m}^{3} / \mathrm{yr}$ in a cross shore section at Narrowneck (located at approximately $6 \mathrm{~km}$ south of the GCS) which is consistent with assessments of the net longshore transport rate in previous studies (Delft, 1970; Patterson, 2007; Splinter et al., 2011). To calculate this rate the accumulative longshore sediment transport for a 1100 metre cross-shore section at the Narrowneck location (ETA67) was determined over the simulated period. The volume, for the 10 month simulation, was approximately $420,000 \mathrm{~m}^{3}$, which is equal to $505,000 \mathrm{~m}^{3} / \mathrm{yr}$ if extrapolated linearly for 12 months; (2) the natural sand bypassing of a portion of littoral drift that leaked from the southern training wall around the seaward edge of the ebb-tidal delta (Figure 3c) as expected for tidal inlets without mechanical sand bypassing (Sha, 1989; FitzGerald et al., 2000); and (3) a tendency of the inlet channel to northward migration, with the ebb tidal delta deflecting northward under the prevailing net longshore transport, which is consistent with the historical behavior of the inlet prior to stabilisation (Figure 3a, b). 

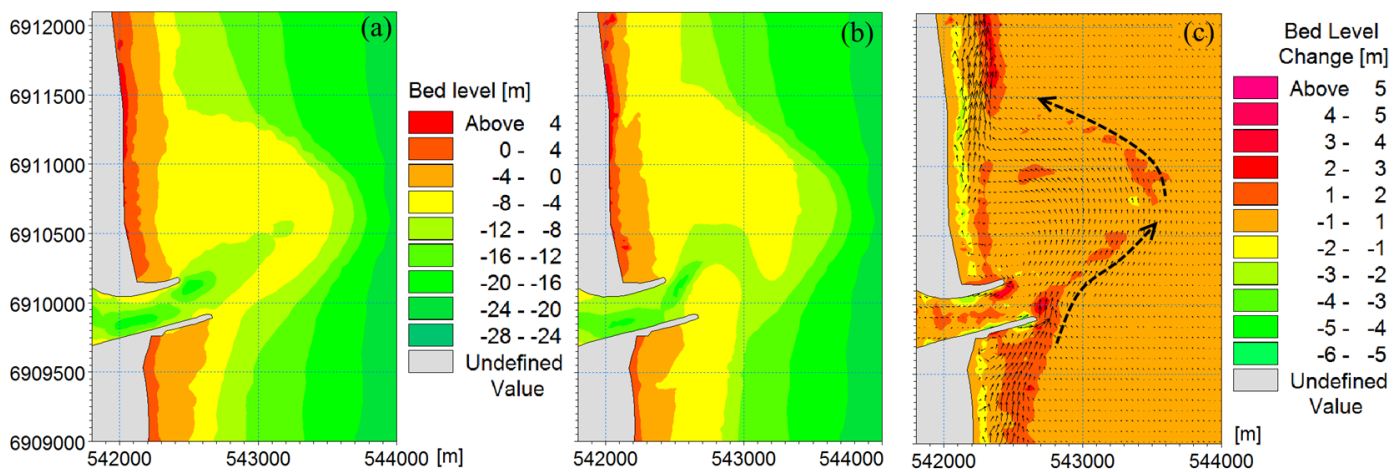

Figure 3. (a) Initial bathymetry in Aug 2008 (b) Final simulated bathymetry for ten month simulation until June 2009 without sand bypassing (c) Natural bypassing around the offshore edge of the delta, sand accumulation upstream southern wall, small arrows indicate the accumulative sediment transport direction (snapshot of bed level change from Aug 2008 until mid Nov 2008)

The ten month simulation also revealed that during fair weather conditions, the sand transported by littoral currents is trapped behind the GCS southern training wall (Figure 3c) which results in a negative sediment budget in South Stradbroke Island (Figure 5). This lack of littoral drift causes the gradual erosion of the downdrift beaches to the north of the northern training wall, as well as at the central part of the ebb-tidal delta (Figure 2). The leakage of littoral drifts seaward of the training wall resulted in accretion near the southern wall of the entrance. In high energy conditions such as the ECL in 2009, owing to more offshore distribution of littoral drift, this leakage is relatively higher. The resulted bathymetry changes of the ten month simulation and survey data are shown in Figure $4 \mathrm{a}$ and $4 \mathrm{c}$. Due to accretion in the southern part of the channel in the model, a more intensive flow jet in the northern channel resulted in an overestimated erosion at the northern part of the entrance mouth compared to the observed morphological evolution with the mechanical sand bypassing (Figure 4a, c). This eroded sand is diverted to the downdrift beaches to partially compensate the lack of littoral transport (Figure 2). It was found that most of the morphological evolution of the ebb-tidal delta during the ten months occurred in response to the ECL in 2009 (Figure 4b, 4c). This is similar to that found in Teign Inlet, UK (

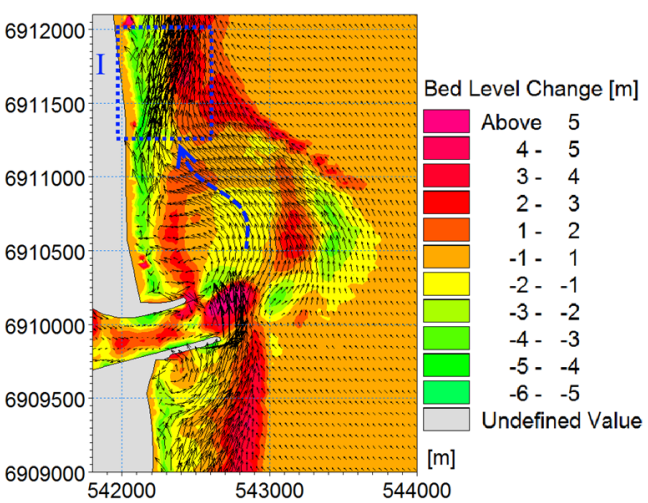

Figure 2. Simulated bed level change for the ten month simulation without sand bypassing. Arrows indicate the accumulative sediment fluxes in ten months. Due to lack of littoral drift downstream, further erosion in area I and central part of ebb-tidal delta is noticeable. al., 2004) where the sediment transport on the ebb-tidal delta primarily depends on the waves. It should be noted that both the ten month and the May 2009 ten day simulations, qualitatively capture most of the

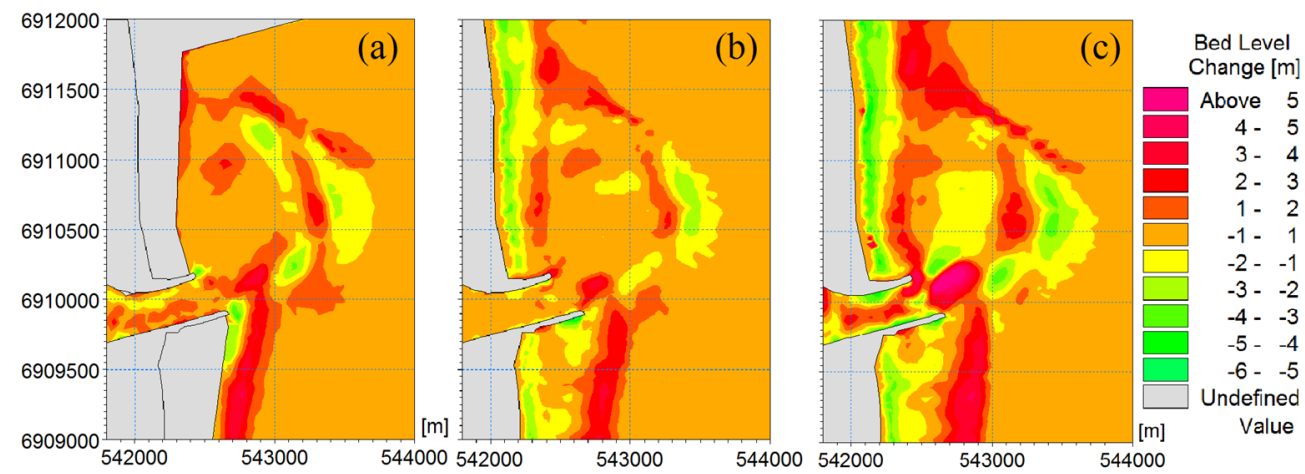

Figure 4. Bed level change (a) between Aug 2008 and Jun 2009 survey data (b) only for the ten day simulation including the ECL in May 2009 storm (c) for the ten month simulation from Aug 2008 to Jun 2009 without simulation of the mechanical sand bypassing (+ : Accretion, -: Erosion) 
morphological evolution patterns in the ebb-tidal delta (Figure 4).

The ten day simulation, including the ECL in 2009, skilfully predicts the morphological evolution of the ebbtidal delta area from August 2008 to June 2009. The overall ABSS skill for the whole area of the survey data (Area A, Figure 5) is 0.64 (good agreement), and only for the ebb-tidal delta (Area B, Figure 5) is 0.55 (fair close to good agreement). The calculated ABSS for the delta crest erosion (Area C, Figure 5) was about 0.83 (excellent agreement, see Table 2). The morphological evolution of area $\mathrm{C}$ was found to be independent of wave breaking, and associated with interactions between the wave induced current before breaking and bathymetry. By varying the sediment size and comparison of resulted Skill Scores, it was also found that slightly coarser sediment size in the domain, specifically in this area, will improve the model prediction of the bed level change. The slightly coarser sand grain size in more offshore areas is consistent with the sediment grain size suggested by Delft (1970). As discussed previously, the ten month simulation over-predicted the erosion of the central part of the ebb tidal delta due to the lack of littoral drift passing the southern wall, and there is a minimum sediment input from the riverine sources as it was confirmed in previous studies (about 9,000 $\mathrm{m}^{3} / \mathrm{yr}$ (Delft, 1970)). Therefore, considering both the ten day and the ten month simulations, it was inferred that the main input source of sediment to the ebb-tidal delta is from the leakage of the

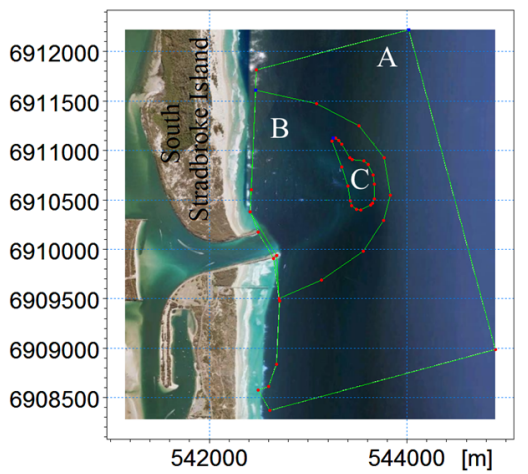

Figure 5. Areas of Skill Score calculation (A) whole survey area (B) only the ebb-tidal delta $(\mathrm{C})$ only the crest of the ebb-tidal delta erosion longshore transport to the ebb-tidal delta. Owing to an offshore shift of the littoral drift during storms, this leakage is more significant during higher energy conditions. Part of the sand transported towards the ebbtidal delta via this leakage then naturally bypasses the delta around its offshore edge, and the remainder is trapped on the ebb-tidal delta area due to the wave and river entrance current interaction.

\section{SUMMARY AND CONCLUSION}

Sediment transport and morphological evolution in GCS area ebb-tidal delta were investigated using depth averaged numerical modelling with MIKE 21, which is couples flow, spectral wave and sediment transport. The model was applied to simulate the morphological evolution of the area between two subsequent surveys (Aug 2008 and June 2009). The model was found to be most sensitive to wave breaking parameter $(\gamma)$, and directional standard deviation (DSD), and sediment mean grain size as well as the applied wave theory in the calculation of the sediment transport rate. The calibrated model was able to accurately simulate the longshore sediment transport, predicting close to the $500,000 \mathrm{~m}^{3} / \mathrm{yr}$ northward estimated in previous studies. The model reproduces several morphological patterns expected for river entrances without the artificial sand bypassing system. These include the sediment accumulation upstream the southern jetty in fair wave condition, natural bypassing of a portion of littoral transport around the offshore edge of the ebb-tidal delta and excessive erosion from the central part of the delta and the downstream coastline due to sand trapping on the south side of the entrance. The excessive erosion of the central part of the ebb-tidal delta is also possibly attributed to increased flow velocities directed towards the north-east in the seaway channel caused by the sand leakage around the southern wall leading to a narrower channel. The resultant morphological change for the ten month simulation suggests that the bulk of the morphological change at the ebb-tidal delta was driven by the ECL in 2009. The overall ABSS Skill Score based on changes occurring during the ECL in 2009 for the whole survey area was 0.64 , suggesting good agreement (Van Rijn et al., 2003). For the ebb-tidal delta area the score was 0.55 (reasonable/fair to good) and for the crest of ebb-tidal delta bed evolution prediction was excellent (score of 0.83 ). Further simulations suggested that adjusting a slightly higher sediment grain size of $220 \mu \mathrm{m}$ to the area can generally improve the model prediction, which will be investigated in future research. Both the ten day and ten month simulations indicate that the main reason contributing to the ebb-tidal delta growth is the leakage of the littoral drift from the bypassing jetty and the southern training wall which occurs mainly during the storm events.

\section{ACKNOWLEDGMENTS}

The survey data used in this research was provided by Gold Coast Waterways Authority and CoGC (City of Gold Coast). 


\section{REFERENCES}

Andrews, M. and Nielsen, C., (2001). Numerical modelling of the Gold Coast Seaway, Proceedings of Coasts \& Ports 2001. Institution of Engineers, Australia, Gold Coast, Australia, pp. 469-474.

Delft, (1970). Gold Coast, Queensland Australia - Coastal erosion and related problems, Report 257, Delft Hydraulics Laboratory, The Netherlands.

Delft, (1992). Southern Gold Coast littoral sand supply, Delft Hydraulics, Gold Coast, Queensland Australia.

DHI, (2014). MIKE 21 \& MIKE 3 flow model FM Sand Transport Module Scientific Documentation.

Doering, J. and Bowen, A., (1995). Parametrization of orbital velocity asymmetries of shoaling and breaking waves using bispectral analysis. Coastal Engineering, 26(1): 15-33.

Fenton, J., (1990). Nonlinear wave theories. the Sea, 9(1): 3-25.

Fenton, J.D., (1985). A fifth-order Stokes theory for steady waves. Journal of waterway, port, coastal, and ocean engineering, 111(2): 216-234.

FitzGerald, D.M., Kraus, N.C. and Hands, E.B., (2000). Natural mechanisms of sediment bypassing at tidal inlets, DTIC Document.

Fortunato, A.B. et al., (2014). Morphological evolution of an ephemeral tidal inlet from opening to closure: the Albufeira inlet, Portugal. Continental Shelf Research, 73: 49-63.

Isobe, M. and Horikawa, K., (1982). Study on water particle velocities of shoaling and breaking waves. Coastal Engineering in Japan, 25: 109-123.

Munday, D., (1995). Coastal response to the Nerang River inlet stabilisation, Gold Coast, Queensland, Australia, QUT, Brisbane.

Patterson, D.C., (2007). Sand Transport and Shoreline Evolution, Northern Gold Coast, Australia. Journal of Coastal Research, SI 50: 147 - 151.

Pinto, L., Fortunato, A.B. and Freire, P., (2006). Sensitivity analysis of non-cohesive sediment transport formulae. Continental Shelf Research, 26(15): 1826-1839.

Sedigh, M., Tomlinson, R., Cartwright, N. and Etemad-Shahidi, A., (under review). Evaluation of the Gold Coast Seaway area hydrodynamics and littoral drift using numerical modelling. Ocean Engineering.

Sedigh, M., Tomlinson, R., Golshani, A. and Cartwright, N., (2012). Long term morphological evolution of the Gold Coast Seaway: Historical and numerical analysis, Coastal Engineering Proceedings.

Sennes, G., Castelle, B., Bertin, X., Mirfenderesk, H. and Tomlinson, R.B., (2007). Modelling of the Gold Coast Seaway tidal inlet, Australia. Journal of Coastal Research, 50: 1086 - 1091.

Sha, L.P., (1989). Variation in ebb-delta morphologies along the West and East Frisian Islands, The Netherlands and Germany. Marine Geology, 89: 11-28.

Siegle, E., Huntley, D.A. and Davidson, M.A., (2004). Physical controls on the dynamics of inlet sandbar systems. Ocean Dynamics, 54(3-4): 360-373.

Splinter, K.D., Golshani, A., Stuart, G. and Tomlinson, R., (2011). Spatial and temporal variability of longshore transport along Gold Coast, Australia, Coastal Engineering Proceedings, pp. sediment. 95.

Sutherland, J., Hall, L. and Chesher, T., (2001). Evaluation of the coastal area model PISCES at Teignmouth (UK). HR Wallingford Report TR125.

Sutherland, J., Peet, A. and Soulsby, R., (2004). Evaluating the performance of morphological models. Coastal Engineering, 51(8): 917-939.

Swart, D.H., (1982). The nature and analysis of random waves in shallow water. Coastal Engineering and Hydraulics Division, National Research Institute for Oceanology, Council for Scientific and Industrial Research.

Tung, T.T., (2011). Morphodynamics of seasonally closed coastal inlets at the central coast of Vietnam. $\mathrm{PhD}$, Delft University of Technology.

Van Rijn, L. et al., (2003). The predictability of cross-shore bed evolution of sandy beaches at the time scale of storms and seasons using process-based profile models. Coastal Engineering, 47(3): 295-327.

WRL and GCCM, (1998). Numerical Modelling of Sediment Movement and Budget at Seaway, Water Research Laboratory in association with Griffith University for GCCC, Gold Coast 